\title{
AVALIAÇÃO DO COMPORTAMENTO GEOQUÍMICO DO SOLO DA REGIÃO DO LIXÃO DE ILHABELA - SP
}

\author{
EVALUATION OF THE GEOCHEMICAL BEHAVIOR OF THE SOIL \\ FROM THE ILHABELA (SP) LANDFILL REGION
}

\author{
Eneas Yosaburo Suzuki ${ }^{1}$; Fábio Taioli ${ }^{1}$ e Cristiane Lorena Rodrigues ${ }^{1}$
}

\begin{abstract}
Recebido em 25/06/2004, Aceito em 11/07/2005
RESUMO O presente trabalho estuda o comportamento do solo da região do lixão de Ilhabela (SP), frente ao contato com o chorume contendo metais pesados. Para tal, foram feitos testes de adsorção nas frações menores que 0,075 $\mathrm{mm}$ com soluções de $\mathrm{Pb}$ e $\mathrm{Ni}$, e na fração menor que $2 \mathrm{~mm}$, utilizando-se o chorume produzido no Aterro São João (município de São Paulo). Foram montadas colunas pelas quais se percolou as soluções controladas de Pb e Ni e também o chorume coletado no Aterro São João. O solo utilizado para os testes foi aquele não impactado amostrado no lixão de Ilhabela, que é utilizado como cobertura dos resíduos gerados no município. Observou-se que os metais são adsorvidos no solo, em sua maioria na fração argilosa e que quando em contato com a fração menor que $2 \mathrm{~mm}$, a quantidade de metais adsorvida é menor que na fração menor que $0,075 \mathrm{~mm}$. O solo da região do lixão de Ilhabela é classificado como areia siltosa, evidenciando a possibilidade de que os metais possam estar chegando à água subterrânea da região, alterando e comprometendo sua qualidade.
\end{abstract}

Palavras Chave: aterro sanitário, lixão, solo, chorume, metais, adsorção, percolação.

ABSTRACT This work presents the behavior of the soil of the Ilhabela landfill region (São Paulo - Brazil) under heavy metals presence in the garbage. It was carried out through a percolation column filled with the local non-impacted soil that was previously fractionated in smaller than $0.075 \mathrm{~mm}$ grain size particles and subjected to the artificial solution of lead $(\mathrm{Pb})$ and nickel $(\mathrm{Ni})$. Another portion of the soil (grain size smaller than $2.0 \mathrm{~mm}$ ) was tested using the urban garbage leachate. For both tests the leachate used was collected at the Aterro São João - São Paulo. The results of the adsorption tests showed that the heavy metals were more concentrated in the soil particles smaller than $0.075 \mathrm{~mm}$ than in the smaller than $2.0 \mathrm{~mm}$ grain size. The results allowed to conclude that the studied material, which is classified as a silty sand soil, where is located the domestic garbage dump of the Ilhabela region, is unsuitable for an efficient retention of heavy metals present in contaminated leachates.

Keywords: landfill, garbage landfill, soil, leachate, metals, adsorption, percolation.

\section{INTRODUÇÃO}

A grande quantidade de lixo gerada no Brasil opriados para sua disposição. Tal problema é particularmente importante no município de Ilhabela - SP (RODRIGUES, 2002). Outro problema é a existência de grande número de lixões como o estudado, que recebe lixo doméstico diariamente da cidade de Ilhabela, sem qualquer tipo de tratamento do terreno, deixando o solo e o aqǘfero freático vulneráveis à contaminação pelo chorume gerado a partir da decomposição do lixo e percolação de água através do mesmo.

Dentre os contaminantes presentes no chorume, destacam-se os metais pesados que, dependendo da sua concentração, poluem o solo, podendo inibir a atividade de enzimas microbióticas e reduzir a diversidade da população da sua fauna e flora. Estes metais podem chegar até os seres humanos por meio do consumo de plantas contaminadas ou pelo atualmente tem ocasionado problemas devido à escassez de novos locais apr consumo de leite ou carne de animais de criação que se alimentem de tais plantas (ALLEN et al., 1994).

\section{OBJETIVOS}

O objetivo deste trabalho foi o estudo geoquímico do solo em um lixão na cidade de Ilhabela - SP perante uma possível contaminação por metais pesados, devido ao chorume gerado a partir dos resíduos sólidos, visto que a análise da capacidade de retenção de metais pesados no solo é um indicador da vulnerabilidade do aqüífero freático.

Além disso, este estudo poderá servir de subsídio para que medidas de prevenção sejam tomadas a fim de se evitar a contaminação do solo e do aquífero freático.

\footnotetext{
${ }^{1}$ Instituto de Geociências - Universidade de São Paulo

(ey_suzuki@yahoo.com.br),(ftaioli@usp.com.br),(c.lorena@servmarunipetro.com.br)
} 


\section{ÁREA DE ESTUDO}

\section{Localização}

A cidade de Ilhabela situa-se no litoral norte do estado de São Paulo, a 220Km da capital. Sua posição geográfica é definida pelos paralelos $23^{\circ}$ $42^{\prime}$ e $23^{\circ} 56^{\prime} \mathrm{S}$ e meridianos $45^{\circ} 41^{\prime}$ e $45^{\circ} 28^{\prime}$ W.

O lixão encontra-se na planície do Perequê, aproximadamente a $5 \mathrm{Km}$ do centro da cidade, através da rodovia SP 131. Sua área é de 65.000 $\mathrm{m}^{2}$ e dista aproximadamente $1000 \mathrm{~m}$ do Oceano Atlântico.

\section{Geologia e Pedologia Regional}

A Ilha de São Sebastião caracteriza-se, a grosso modo, como um maciço alcalino encaixado em estruturas gnáissicas. Ela é constituída por rochas granitóides de idade PréCambriana, diques básicos e diques de composição ultrabásica e alcalina de dimensões menores, três stocks de rochas alcalinas e um corpo menor de natureza básico-alcalina e depósitos sedimentares recentes derivados das rochas mais antigas e que estão associados às encostas, rede de drenagem e à zona costeira (HENNIES; HASUI 1977). A Figura 1 apresenta o mapa geológico da Ilha de São Sebastião.

Com base no Sistema Brasileiro de Classificação de Solos da EMBRAPA (1999) e adotadas em Oliveira (1999), o solo da ilha de São Sebastião é caracterizado como um Cambissolo Háplico, sendo constituído por material mineral, que apresenta horizonte $\mathrm{A}$ ou hístico com espessura menor que $40 \mathrm{~cm}$ seguido de horizonte $B$ incipiente e satisfazendo os seguintes requisitos: $\mathrm{B}$ incipiente não coincidente com horizonte glei dentro de $50 \mathrm{~cm}$ da superfície do solo; B incipiente não coincidente com horizonte plíntico; B incipiente não coincidente com o horizonte vértico dentro de $100 \mathrm{~cm}$ da superfície do solo; e não apresentar a conjugação de horizonte A chernozênico e horizonte B incipiente com alta saturação por bases e argila de atividade alta.

\section{MATERIAL E MÉTODOS}

A metodologia empregada envolveu uma primeira etapa que compreendeu os trabalhos de campo com coletas de amostra de solo não impactado na área do lixão de Ilhabela e amostras de chorume tanto do lixão de Ilhabela como também do aterro sanitário Sítio São João, este localizado na cidade de São Paulo. A segunda etapa compreendeu as análises e ensaios laboratoriais das amostras de solo e chorume. A terceira etapa abrangeu o tratamento dos dados e a quarta etapa a apresentação e discussão dos resultados obtidos.

\section{Solo}

Após preparação do solo, por meio de secagem, destorroamento e quarteamento, o mesmo foi submetido a análises granulométrica e química no Laboratório de Sedimentologia e Laboratório de Química do DGG respectivamente, ambos do Instituto de Geociências da USP.

Foi realizada ainda Difratometria de RaiosX, também no Laboratório de Química do DGG, utilizando-se o Método do Pó com a fração argila do solo.

\section{Chorume}

Devido ao potencial poluidor relativamente baixo do chorume do lixão de Ilhabela, optou-se por utilizar o chorume do aterro São João nos ataques químicos e ensaios de percolação, uma vez que as características dos resíduos depositados em ambos locais são semelhantes.

$\mathrm{O}$ chorume foi coletado em uma das lagoas de armazenamento do aterro São João e acondicionado em frascos plásticos. Em seguida foi armazenado sob refrigeração a aproximadamente $4{ }^{\circ} \mathrm{C}$ e encaminhado para o laboratório.

As análises químicas do chorume do lixão de Ilhabela foram realizadas por Espectrômetro de Emissão Atômica com Plasma Induzido ICP AES modelo ARL - 3410 da Applied Research Laboratories. Após os ensaios de percolação, adsorção e ataques com chorume (aterro São João) o mesmo foi analisado por Espectrofotometria de Absorção Atômica com forno de grafite. 


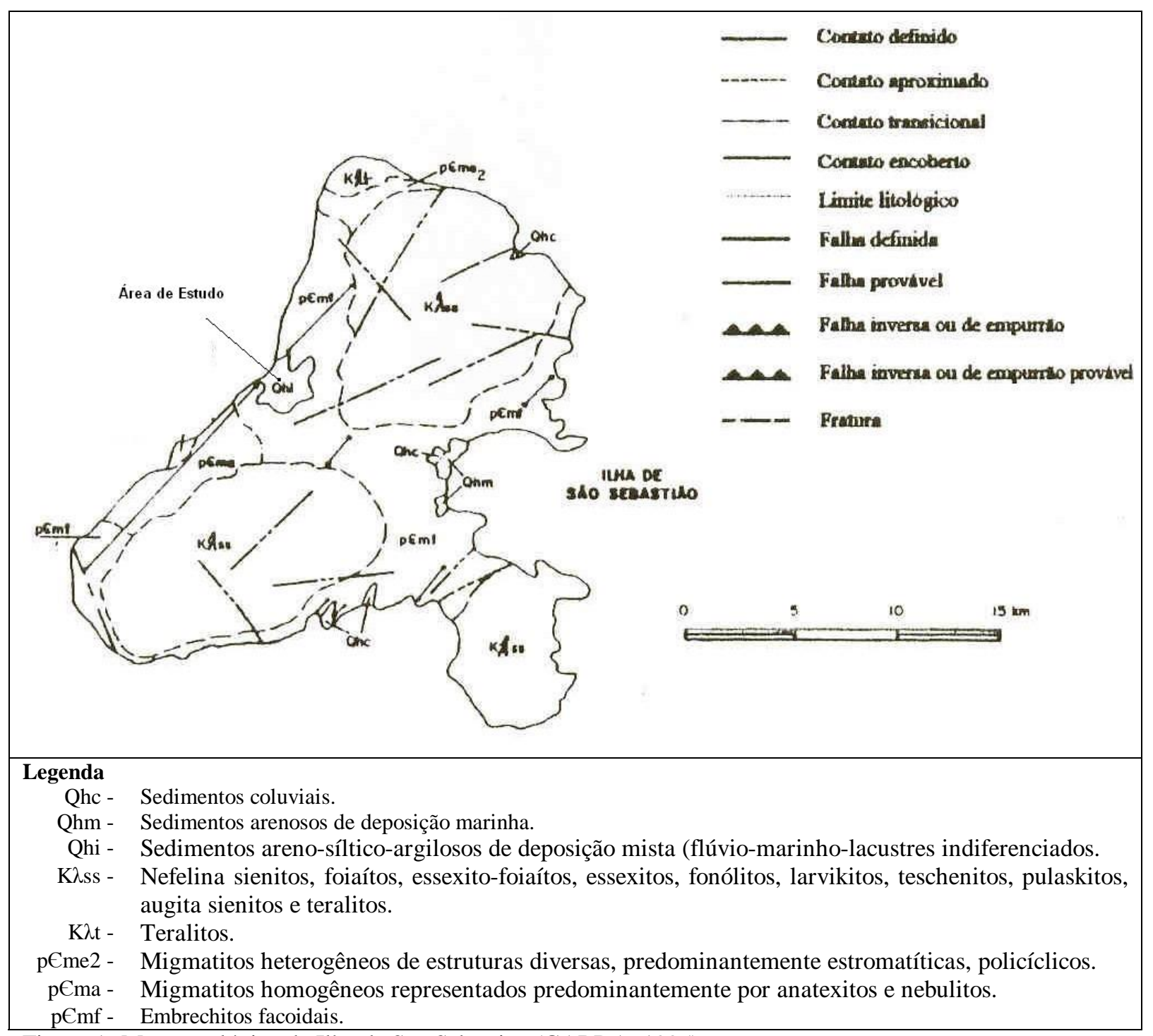

Figura 1- Mapa geológico da Ilha de São Sebastião (GARDA, 1995).

Figure 1 - Geological map of the São Sebastião island (GARDA., 1995). 


\section{Ensaios de Adsorção}

Geralmente, estudos de adsorção em laboratório batch test são usados para determinar a capacidade do solo em reter um elemento específico.

O procedimento consistiu no peneiramento, quarteamento e preparação de amostras com a fração até $0,075 \mathrm{~mm}$ do solo. Para cada metal a ser estudado foram preparadas 7 amostras com 15,000 g e denominadas da seguinte maneira:

-Para o Pb: Bt-Pb 1, Bt-Pb 2, Bt-Pb 3, Bt-Pb 4, $\mathrm{Bt}-\mathrm{Pb} 5$, Bt-Pb 6 e Bt-Pb 7;

-Para o Ni: Bt-Ni 1, Bt-Ni 2, Bt-Ni 3, Bt-Ni 4, Bt-Ni 5, Bt-Ni 6 e Bt-Ni 7.

A partir de uma solução stock de 1000 ppm foram preparados padrões de 0,5, 1, 2, 4, 5, $10 \mathrm{e}$ $20 \mathrm{ppm}$ de $\mathrm{Ni}$ e $\mathrm{Pb}$, foram analisadas da seguinte maneira: as de níquel por ICP-AES e as de $\mathrm{Pb}$ pelo método de absorção atômica, determinandose assim os valores reais das concentrações iniciais para o teste de adsorção.

A cada amostra do solo foram adicionados $200 \mathrm{~mL}$ da solução. As soluções permaneceram em contato com o solo por 7 dias, com agitação eventual. Após este período o solo foi separado da solução por filtração e a concentração do filtrado foi determinada novamente por meio de absorção atômica (para o $\mathrm{Pb}$ ) e por ICP-AES para o Ni obtendo-se as concentrações finais. A massa adsorvida foi determinada pela diferença entre a concentração inicial e final, normalizada pelo volume utilizado de acordo com a equação 1 (Fetter, 1994) e o resultado expresso como a massa adsorvida pela massa de solo utilizada no teste.

$\mathrm{C}^{*}=[(\mathrm{Ci}-\mathrm{Cf}) \mathrm{xVs}] / \mathrm{M}$, equação 1

onde:

-Ci: concentração inicial da solução (mg/L);

-Cf: concentração final da solução (mg/L);

-Vs: volume da solução $(\mathrm{mL})$;

-M: massa da amostra (g);

$-\mathrm{C}^{*}$ : quantidade adsorvida $(\mu \mathrm{g} / \mathrm{g})$.

De acordo com Fetter (1994) foram plotados gráficos de $\mathrm{C}^{*}$ versus $\mathrm{Cf}$ tanto para chumbo como para níquel.

Um segundo teste de adsorção foi elaborado utilizando-se massas de solo conhecidas (aproximadamente $15 \mathrm{~g}$ ) e de granulometria até 2, $0 \mathrm{~mm}$, colocados em 8 beckers de $400 \mathrm{~mL}$ aos quais foram adicionadas alíquotas de $50 \mathrm{~mL}$ de chorume.

As amostras foram designadas de ATCH 1, ATCH 3, ATCH 5, ATCH 7, ATCH 10, ATCH 15, ATCH 20 e ATCH 30. O número da amostra corresponde ao número de dias que esta permaneceu em contato com o chorume.
Após o número de dias determinado, a solução foi separada do solo por meio de filtros de papel de filtração lenta. A solução foi acidulada com $\mathrm{HNO}_{3}$ até atingir $\mathrm{pH}$ inferior a 2 e avolumada para $100 \mathrm{~mL}$. As soluções filtradas foram analisadas por absorção atômica.

\section{Ataque Químico}

Para determinação da concentração dos metais de interesse nas amostras ATCH 1, ATCH 7, ATCH 15 e ATCH 30 após os ensaios de adsorção, as mesmas foram secas a temperatura ambiente e separadas $1,0000 \mathrm{~g}$ de cada amostra, pesadas em balança analítica e atacadas com ácido nítrico a quente; as soluções geradas foram encaminhadas para análise química.

\section{Ensaios de Percolação}

Para o ensaio de percolação foi utilizado um extrator tipo soxhlet cuja coluna de vidro possui $30,0 \mathrm{~cm}$ de comprimento por $7,0 \mathrm{~cm}$ de diâmetro, com um sifão a $14,5 \mathrm{~cm}$ de altura.

Foram realizados 3 ensaios de percolação: um utilizando-se chorume como percolante e outros dois utilizando-se soluções de chumbo e níquel, de concentrações 1,297 ppm e 2,038 ppm respectivamente. Todos os ensaios foram conduzidos com os mesmos procedimentos.

Uma amostra de solo com cerca de $50 \mathrm{~g}$ e granulometria até $2,0 \mathrm{~mm}$ foi acondicionada em um cartucho permeável de algodão que foi colocado dentro da coluna de vidro do extrator tipo soxhlet. Um volume de líquido (chorume ou solução de $\mathrm{Pb}$ ou $\mathrm{Ni}$ ) de $600 \mathrm{~mL}$ foi gotejado dentro da coluna de vidro a um fluxo constante $(50 \mathrm{~mL} / \mathrm{h})$. O volume de $600 \mathrm{~mL}$ foi o necessário para preencher a coluna de vidro até o nível do líquido atingir o sifão, quando ocorre o refluxo e a coluna é esvaziada. O líquido foi coletado e colocado novamente para gotejar, formando um ciclo contínuo durante um período de 7 dias.

Após o último refluxo o líquido foi acidulado com $\mathrm{HNO}_{3} \quad(\mathrm{pH}<2)$ e levado à análise por absorção atômica e o solo por Microscópio Eletrônico de Varredura, em detector de retroespalhado em aumento de até 1.700 vezes juntamente com espectrometria de energia dispersiva (EDS) de Raios-X.

As amostras dos ensaios de percolação com soluções de $\mathrm{Pb}$ e $\mathrm{Ni}$ foram denominadas de Coluna- $\mathrm{Pb}$ e Coluna-Ni, respectivamente. E para o ensaio de percolação com chorume, a amostra foi chamada de Coluna-ch. 


\section{RESULTADOS OBTIDOS}

Solo

A análise química do solo utilizado para os ensaios apresentou os resultados mostrados na tabela 1.

De acordo com a análise granulométrica, o solo tem pequena porcentagem de argila, sendo sua maior parte compreendida na fração arenosa, como pode ser visto na tabela 2 . Com base na classificação em diagrama triangular o solo é descrito como uma areia siltosa (PETTIJOHN, 1975).

A difratometria de Raios-X (Figura 2) da amostra En 01 do solo evidenciou uma associação entre hematita e goethita e argilas do grupo da Caulinita e grupo da Ilita. Portanto a capacidade de adsorção deste solo não se limita às argilas, uma vez que a goethita também é capaz de interagir com os metais.

Tabela 1- Porcentagem de óxidos presentes no solo do lixão de Ilhabela

Table 1 - Percentage of oxides present in the Ilhabela landfill soil

\begin{tabular}{c|c|c|c|c|c|c|c|c|c}
\hline $\begin{array}{c}\mathrm{SiO}_{2} \\
(\%)\end{array}$ & $\begin{array}{c}\mathrm{Al}_{2} \mathrm{O}_{3} \\
(\%)\end{array}$ & $\begin{array}{c}\mathrm{Fe}_{2} \mathrm{O}_{3} \\
(\%)\end{array}$ & $\begin{array}{c}\mathrm{MgO} \\
(\%)\end{array}$ & $\begin{array}{c}\mathrm{CaO} \\
(\%)\end{array}$ & $\begin{array}{c}\mathrm{Na}_{2} \mathrm{O} \\
(\%)\end{array}$ & $\begin{array}{c}\mathrm{K}_{2} \mathrm{O} \\
(\%)\end{array}$ & $\begin{array}{c}\mathrm{P}_{2} \mathrm{O}_{5} \\
(\%)\end{array}$ & $\begin{array}{c}\mathrm{MnO} \\
(\%)\end{array}$ & $\begin{array}{c}\mathrm{TiO}_{2} \\
(\%)\end{array}$ \\
\hline 65,7 & 18,11 & 5,26 & 0,79 & 20,01 & 0,13 & 2,78 & 0,03 & 0,06 & 0,69 \\
\hline
\end{tabular}

Tabela 2 - Distribuição granulométrica do solo do lixão de Ilhabela

Table 2 - Grain-size distribution of the Ilhabela landfill soil

\begin{tabular}{c|c|c|c|c|c|c|c}
\hline Amostra & $\begin{array}{c}\text { Argila } \\
(\%)\end{array}$ & $\begin{array}{c}\text { Silte fino } \\
(\%)\end{array}$ & $\begin{array}{c}\text { Silte grosso } \\
(\%)\end{array}$ & $\begin{array}{c}\text { Areia fina } \\
(\%)\end{array}$ & $\begin{array}{c}\text { Areia grossa } \\
(\%)\end{array}$ & $\begin{array}{c}\text { Umidade } \\
(\%)\end{array}$ & $\begin{array}{c}\text { Total } \\
(\%)\end{array}$ \\
\hline En 01 & 10,91 & 13,56 & 4,61 & 24,91 & 44,99 & 1,21 & 100,19 \\
\hline
\end{tabular}

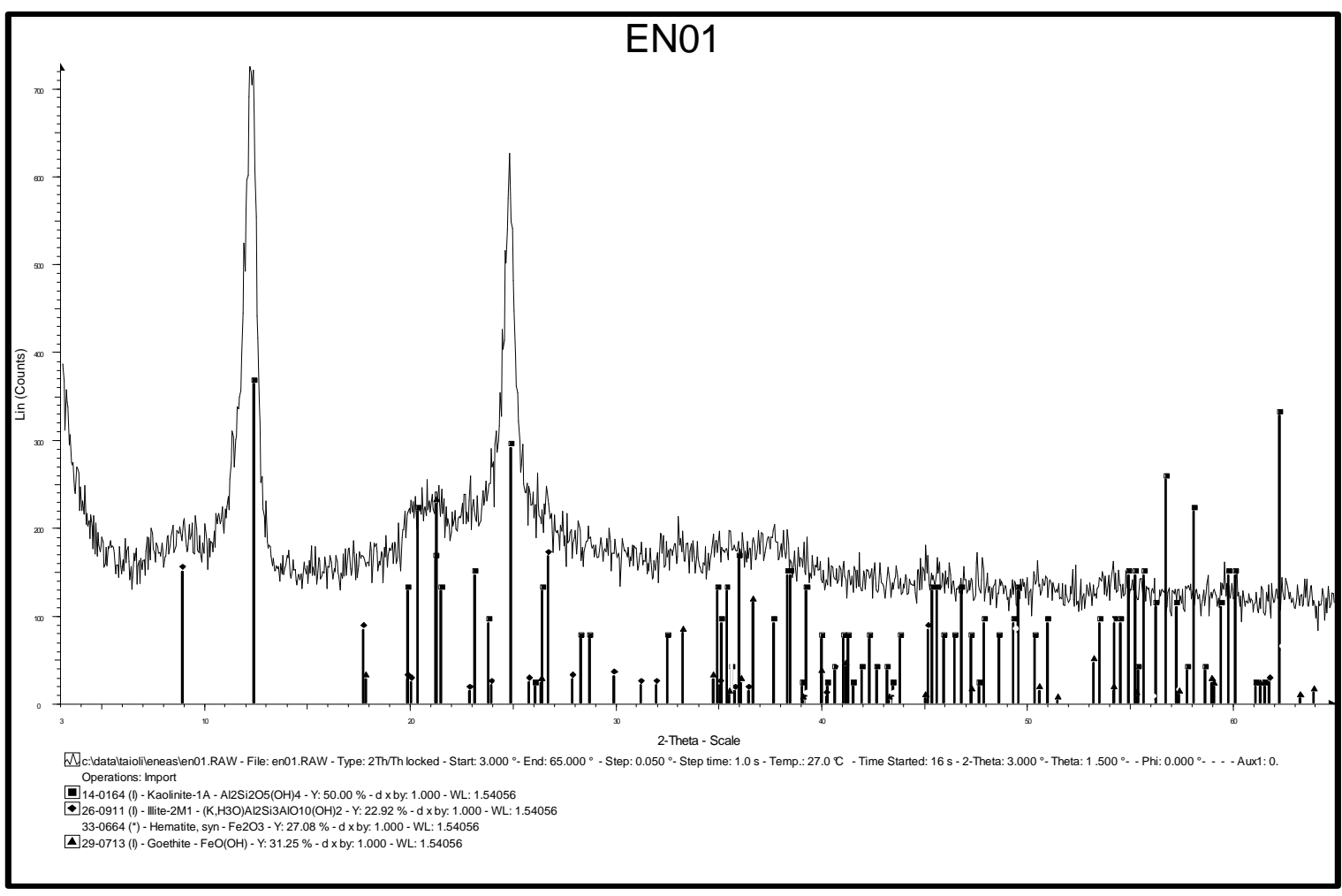

Figura 2 - Difratograma de Raios-X da amostra EN-01

Figure 2 - X-ray difratogram of the EM-01 sample 


\section{Microscópio Eletrônico de Varredura}

Após a percolação do solo com o chorume, uma amostra do mesmo foi analisada por MEV, em detector de retro-espalhado em aumento de até 1.700 vezes em imagem de detector de elétrons retro-espalhados juntamente com espectrometria de energia dispersiva (EDS) de Raios-X (Figura 3). No entanto não foram encontrados os metais em estudo (chumbo e níquel) ou minerais secundários.

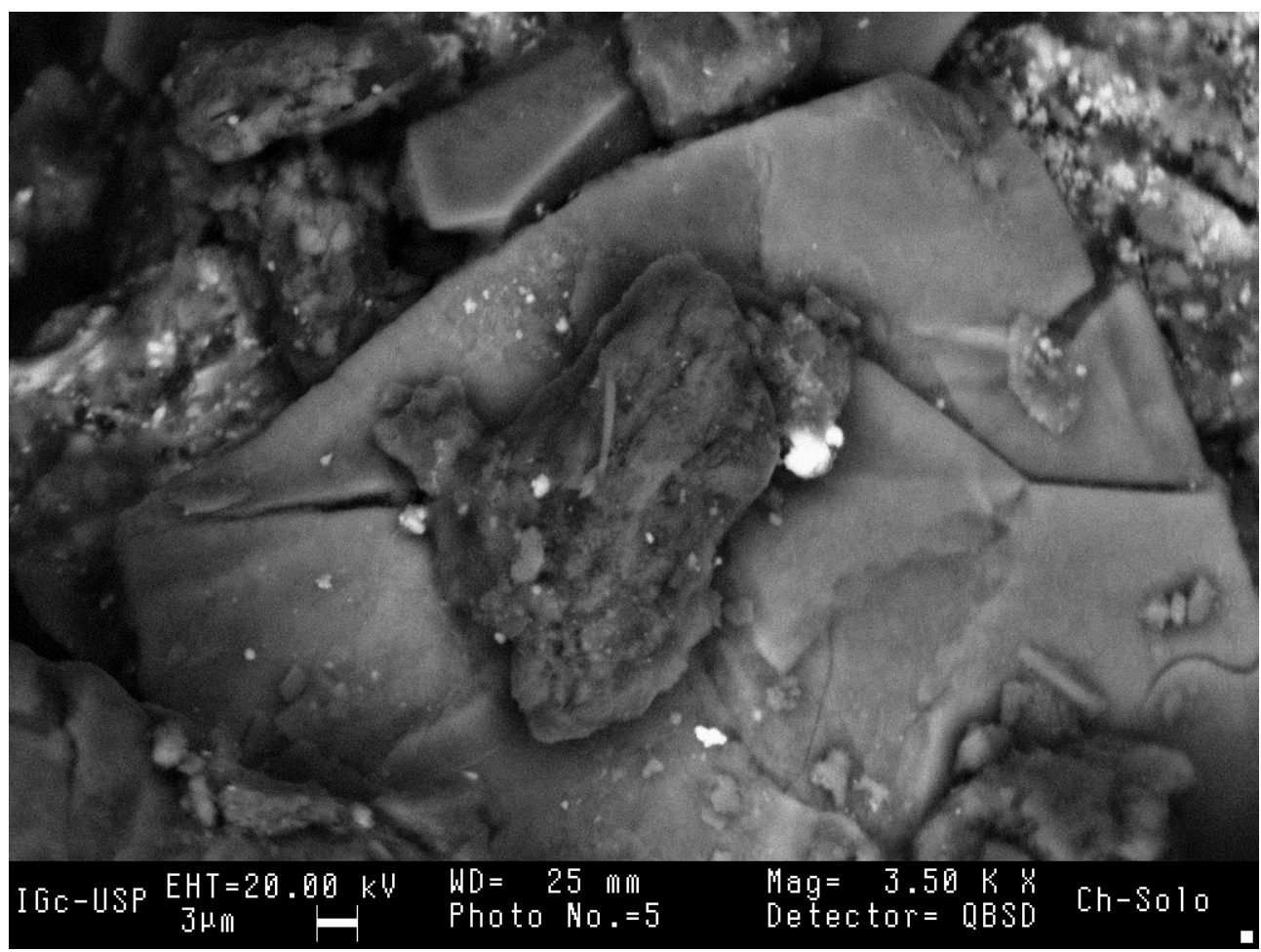

Figura 3- Imagem obtida durante as análises da amostra de solo por MEV. Figure 3 - Scanning Electron Microscope Image of the soil sample

\section{Chorume}

A tabela 3 mostra os resultados das análises do chorume coletado no lixão de Ilhabela e também no aterro São João.

\section{Ensaios de Adsorção e Percolação}

Foram feitas análises das alíquotas de chorume e amostras de solo provenientes do ensaio de adsorção para os metais $\mathrm{Ba}^{0}, \mathrm{~Pb}^{0}, \mathrm{Cu}^{0}$, $\mathrm{Cr}^{0}, \mathrm{Fe}^{0}, \mathrm{Mn}^{0}, \mathrm{Ni}^{0}$ e $\mathrm{Zn}^{0}$. No entanto $\mathrm{Cr}^{0}$ não pôde ser estudado por apresentar valores menores que o detectável pelo método utilizado $(<0,05 \mathrm{mg} / \mathrm{L})$. Foram analisadas as amostras de solo correspondentes às amostras ATCH 1, ATCH 7, ATCH 15, ATCH 30 e o solo não impactado, denominado de ZERO, para se comparar com os resultados das alíquotas de chorume. A concentração inicial do chorume (antes dos ensaios de adsorção) também foi chamada de ZERO.
Tabela 3- Análise química das amostras de chorume.

Table 3 -Chemical analysis of the leachate samples

\begin{tabular}{c|c|c|c}
\hline \multicolumn{4}{|c}{ lixão de Ilhabela } \\
\hline Elemento & $\begin{array}{c}\text { Concentração } \\
(\mathrm{ppm})\end{array}$ & Elemento & $\begin{array}{c}\text { Concentração } \\
(\mathrm{ppm})\end{array}$ \\
\hline $\mathrm{Na}$ & $>999$ & $\mathrm{Ni}$ & 0,114 \\
$\mathrm{Mg}$ & 93,100 & $\mathrm{Cu}$ & 0,011 \\
$\mathrm{Al}$ & 0,173 & $\mathrm{Zn}$ & 0,053 \\
$\mathrm{~K}$ & 470,000 & $\mathrm{Sr}$ & 0,588 \\
$\mathrm{Ca}$ & 111,000 & $\mathrm{Cd}$ & 0,004 \\
$\mathrm{Cr}$ & 0,047 & $\mathrm{Ba}$ & 0,355 \\
$\mathrm{Mn}$ & 0,179 & $\mathrm{~Pb}$ & 0,002 \\
$\mathrm{Fe}$ & 1,430 & & \\
\hline \multicolumn{4}{|c}{}
\end{tabular}

\begin{tabular}{c|c|c|c}
\hline \multicolumn{4}{|c}{ Aterro São João } \\
\hline Elemento & $\begin{array}{c}\text { Concentração } \\
(\mathrm{ppm})\end{array}$ & Elemento & $\begin{array}{c}\text { Concentração } \\
(\mathrm{ppm})\end{array}$ \\
\hline $\mathrm{Ba}$ & 0,067 & $\mathrm{Fe}$ & 4,876 \\
$\mathrm{~Pb}$ & 0,284 & $\mathrm{Mn}$ & 0,094 \\
$\mathrm{Cu}$ & 0,120 & $\mathrm{Ni}$ & 0,268 \\
$\mathrm{Cr}$ & $<0,05$ & $\mathrm{Zn}$ & 0,505 \\
\hline
\end{tabular}




\section{Tratamento dos Dados}

Os resultados não são correlacionáveis diretamente uma vez que as somas das concentrações iniciais e finais dos elementos, no sistema solo-chorume, não são as mesmas. Deste modo optou-se por uma análise percentual onde foram somadas as concentrações das amostras de solo e chorume iniciais (antes da percolação), fazendo desta soma um valor igual a $100 \%$ e determinando-se a porcentagem correspondente a

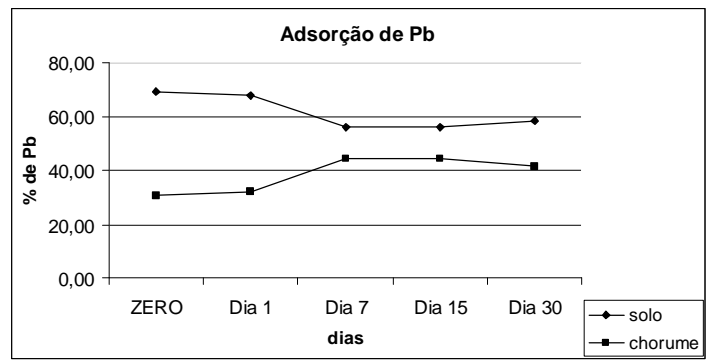

Figura 4 - Porcentagem de $\mathrm{Pb}$ adsorvida no solo e chorume em função do tempo.

Figure 4 - Percentage of $\mathrm{Pb}$ adsorbed in the soil and in the leachate as function of the time

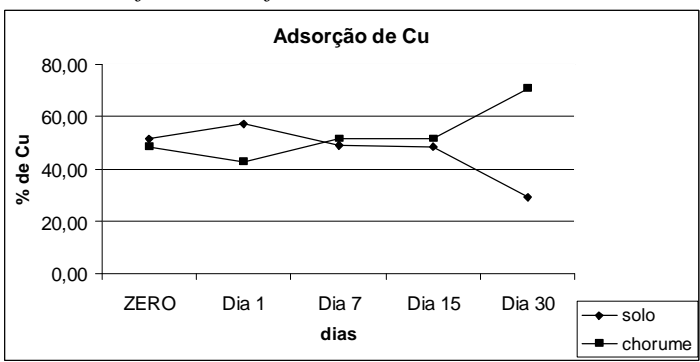

Figura 6 - Porcentagem de $\mathrm{Cu}$ adsorvida no solo e chorume em função do tempo.

Figure 6-Percentage of $\mathrm{Cu}$ adsorbed in the soil and in the leachate as function of the time

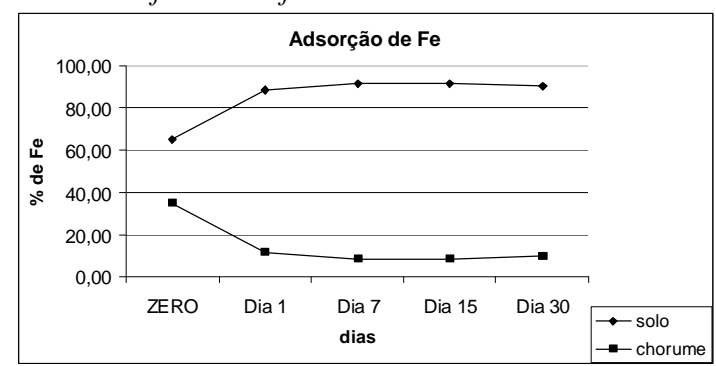

Figura 8 - Porcentagem de Fe adsorvida no solo e chorume em função do tempo.

Figure 8 - Percentage of Fe adsorbed in the soil and in the leachate as function of the time

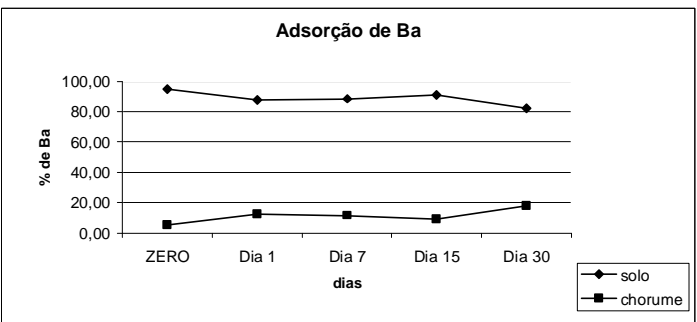

Figura 10 - Porcentagem de Ba adsorvida no solo e chorume em função do tempo.

Figure 10 - Percentage of $\mathrm{Ba}$ adsorbed in the soil and in the leachate as function of the time cada termo da soma.

Os resultados dos ensaios de adsorção e percolação com o chorume são apresentados simultaneamente a fim de permitir a comparação entre ambos. Tais resultados estão na forma de gráficos para melhor visualização do comportamento entre os componentes do solo e do chorume (Figuras 4, 5, 6, 7, 8, 9 e10).

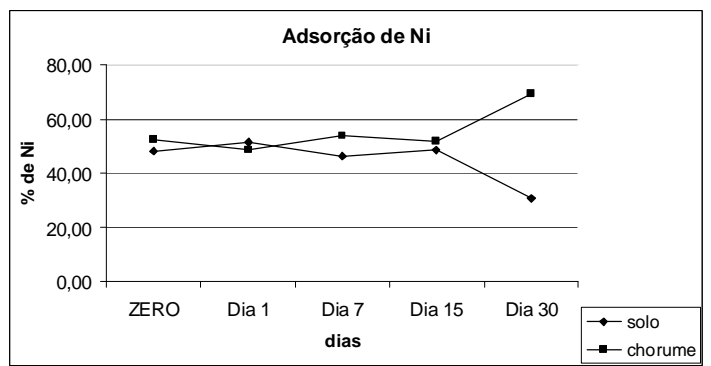

Figura 5 - Porcentagem de Ni adsorvida no solo e chorume em função do tempo.

Figure 5 - Percentage of $\mathrm{Ni}$ adsorbed in the soil and in the leachate as function of the time

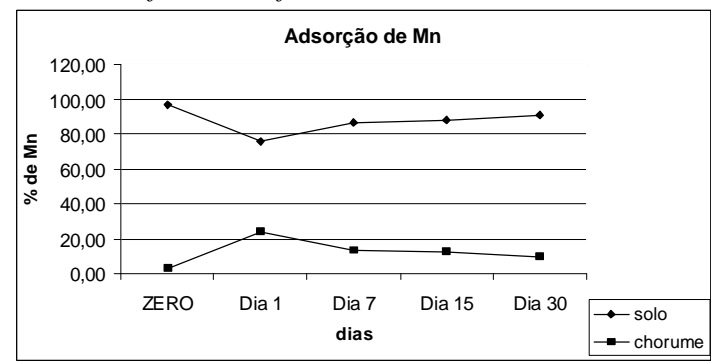

Figura 7 - Porcentagem de Mn adsorvida no solo e chorume em função do tempo.

Figure 7 - Percentage of Mn adsorbed in the soil and in the leachate as function of the time

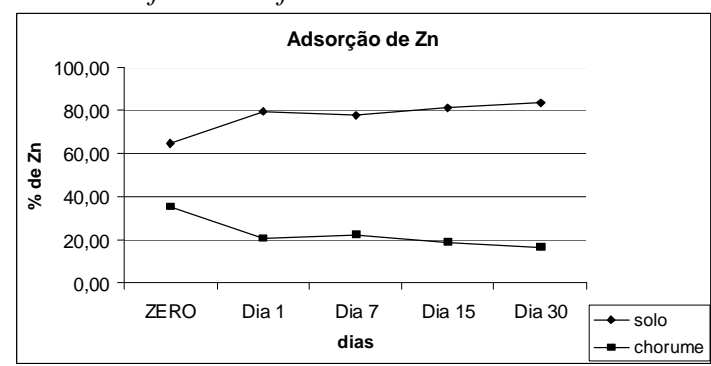

Figura 9 - Porcentagem de $\mathrm{Zn}$ adsorvida no solo e chorume em função do tempo.

Figure 9 - Percentage of $\mathrm{Zn}$ adsorbed in the soil and in the leachate as function of the time 
Os ensaios de adsorção e percolação, utilizando-se soluções dos metais chumbo e níquel, apresentaram resultados que foram

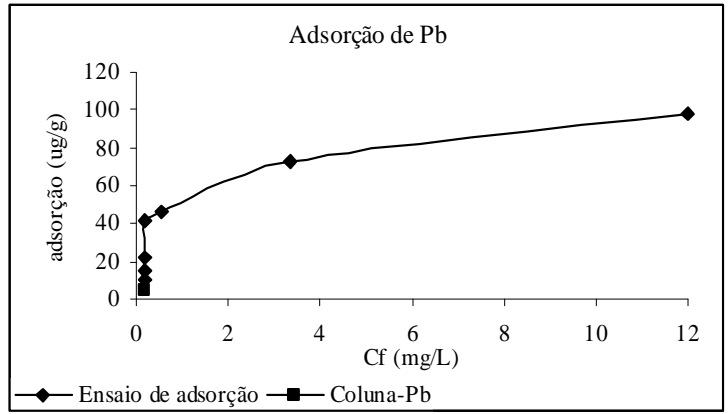

Figura 11: Gráfico de adsorção de $\mathrm{Pb}$ no solo

Figure 11 - Graph showing the Pb adsorption in the soil

\section{INTERPRETAÇÃO E DISCUSSÃO DOS RESULTADOS}

Os ensaios de adsorção e percolação com soluções de $\mathrm{Pb}$ e $\mathrm{Ni}$ previamente preparadas mostraram uma adsorção crescente para o chumbo sem ter atingido um nível de estabilização, enquanto para o níquel observou-se concentrações variadas tendendo a uma concentração de estabilização em torno de 7,5 $\mu \mathrm{g} / \mathrm{g}$. A maior adsorção ocorreu no solo de granulometria até $0,075 \mathrm{~mm}$ em que o solo e a solução permaneceram em repouso. Já nos ensaios de percolação em solo com granulometria maior (até 2,0 mm) em que o contato entre a solução e o solo era dinâmico, a adsorção foi consideravelmente menor, sobretudo para o Ni. Isto evidencia a maior capacidade de retenção nas frações de menor granulometria do solo, como é relatado na literatura.

Os resultados evidenciam a ocorrência de interação entre o solo e o chorume, e a adsorção dos metais pesados mostrou ser um mecanismo complexo e dinâmico, uma vez que há uma variação não linear das concentrações destes metais no chorume e no solo.

Alguns metais apresentaram similaridades em suas curvas de adsorção, como é o caso do cobre e do níquel, assim como ferro e zinco. As curvas obtidas para ferro e manganês indicam um tipo de "competição" entre eles, que pode estar ligada à incorporação destes elementos à estrutura cristalina de algum mineral que, no entanto, não foi identificado pela análise por MEV. colocados em gráficos de Adsorção (em $\mu \mathrm{g} / \mathrm{g}$ ) versus a concentração final da solução (após ter permanecido em contato com o solo). Os gráficos são apresentados nas Figuras 11 e 12.

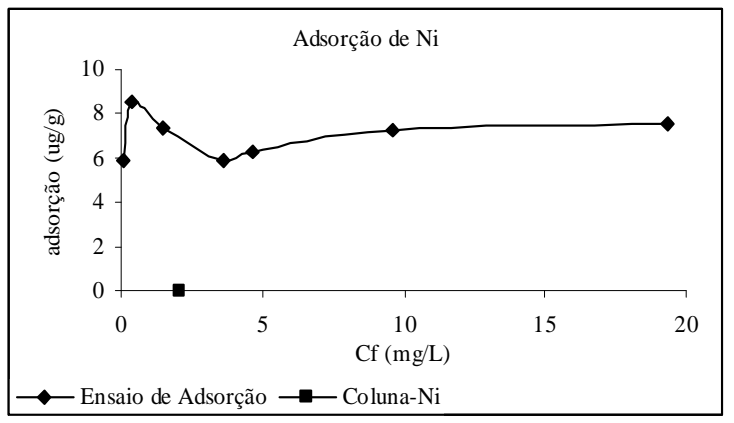

Figura 12: Gráfico de adsorção de Ni no solo

Figure 12 - Graph showing the Ni adsorption in the soil

\section{CONCLUSÕES}

A análise do comportamento do solo perante uma exposição ao chorume e contaminação por metais pesados é um estudo complexo que exige a integração de várias técnicas analíticas e dados bibliográficos. A interpretação dos resultados obtidos permite as seguintes conclusões:

a) ocorre interação entre o solo e o chorume evidenciada tanto pelos ensaios de adsorção como de percolação;

b) a interação entre os metais pesados, presentes no chorume, e o solo é complexa e dinâmica, parecendo haver uma espécie de "competição" entre os mesmos, particularmente entre o Fe e Mn;

c) além da simples adsorção, pode estar ocorrendo complexação dos metais pesados o que mascara sua detecção por análises químicas;

d) os ensaios de adsorção utilizando soluções de um só metal apresentam a limitação de não proporcionar meios de avaliação de eventuais "competições" entre diferentes elementos;

e) a baixa porcentagem de argila do solo da área do lixão sugere uma baixa capacidade de retenção dos metais pesados possibilitando que estes atinjam a água subterrânea. No entanto, não foram feitas análises químicas da água do aquíffero freático local;

f) o ataque com chorume e os resultados das análises químicas do solo mostraram a suscetibilidade do mesmo à contaminação, evidenciando a necessidade de implantação de um programa de monitoramento ambiental na área do lixão. 


\section{REFERÊNCIAS}

ALLEN, H. E.; HUANG, C. P.; BAILEY, G. W.; BOWERS, A. R. Metal Speciation and Contamination of Soil. Lewis Publishers. 358p. 1994.

EMBRAPA. Sistema Brasileiro de Classificação de Solos. Brasília: Embrapa Produção de Informação, 1999. 412p.

FETTER, C. W. Applied Hydrogeology. PrenticeHall, Inc. Third Edition, 691p. 1994.

GARDA, G. M. Diques Básicos e Ultrabásicos da Região Costeira Entre as Cidades de São Sebastião e Ubatuba, Estado de São Paulo. São Paulo, 1995. Tese de Doutorado - Instituto de Geociências - USP. $156 \mathrm{p}$.

HENNIES, W. T.; HASUI, Y. Contribuição ao Reconhecimento da Geologia da Ilha de São Sebastião. I Simpósio de Geologia Regional, São Paulo, Atas; p. 199 - 209. 1977.
OLIVEIRA, J. B. Solos do Estado de São Paulo: descrição das classes registradas no mapa pedológico. Boletim Científico, Instituto Agronômico, Campinas (SP), n 45. 108p. 1999.

PETTIJOHN, F. J. Sedimentary Rocks. New York, Harper \& Row,Publishers. 628p. 1975.

RODRIGUES, C. L. Avaliação do Potencial de Contaminação do Lixão de Ilhabela - SP. São Paulo. 2002. Dissertação de Mestrado - Instituto de Geociências da USP. 98p.

\section{AGRADECIMENTOS}

A presente pesquisa contou com o apoio da Fundação de Amparo à Pesquisa no Estado de São Paulo FAPESP, processo 00/11897-0. Os autores agradecem também ao Centro de Pesquisa de Águas Subterrâneas - CEPAS do IGc-USP, que disponibilizou a infraestrutura para os ensaios de bancada. 
Avaliação do comportamento geoquímico do solo da região do lixão de Ilhabela - SP 